\title{
La universalidad de los derechos humanos: una apuesta por la multiculturalidad de los pueblos indígenas en Colombia
}

\author{
The universality of human rights: a commitment to the multiculturalism of \\ indigenous peoples
}

\begin{abstract}
Carolina García Sánchez ${ }^{*}$, Alejandra Hernández Ospina **
*Candidata doctoral en filosofía, Magister en Filosofía, profesional en filosofía y letras. Catedrática en la escuela superior de administración pública y integrante del grupo de investigación Gobierno, Territorio y Cultura. Docente en el programa de Filosofía de la universidad del Quindío. Armenia, Quindío, Colombia. carolina.garcia@esap.edu.co ** Profesional en Administración Pública. Históriadora. Universidad de Caldas. Manizales, Caldas.
\end{abstract}

Fecha de recepción: mayo 10 de 2021 Fecha de aprobación: junio 15 de 2021

Para citar este artículo / To reference this article García, C., Hernández, A., (2021) La universalidad de los derechos humanos: una apuesta por la multiculturalidad de los pueblos indígenas en Colombia.. Inciso, 23(1) , e 1043

DOl: http://dx.doi.org/10.18634/incj.22v.2i1043

\section{Resumen}

En el presente artículo se afirma que, la "universalidad" de los derechos entra en una contradicción ontológica, frente a su figura jurídica, en tanto; de un lado, se busca que todos los pueblos accedan de manera homogénea a los mismos "derechos" y, de otro lado, se desconoce la heterogeneidad de las variedades culturales de las comunidades. Para defender dicha afirmación se toma por referente teórico los planteamientos de Foucault $(1998,1999)$ y Galtung (1969) sobre el ejercicio de dominación y de violencia estructural que ha surgido gracias a la globalización. Se toma por estudio al resguardo indígena de San Lorenzo, ubicado en el municipio de Supía, departamento de Caldas en la zona andina colombiana. Para ello; primero, se analiza el planteamiento de la universalidad de los derechos humanos y, en especial, de los derechos de los pueblos indígenas; segundo, se analiza la noción de universalidad de los derechos teniendo por caso de análisis al resguardo indígena de San Lorenzo y; tercero, se concluye que pese a que la universalidad de derechos atenta directamente contra la ancestralidad de los pueblos 
indígenas, estos vienen desarrollando estrategias comunitarias para garantizar la pervivencia multicultural de los pueblos.

Palabras clave: Derecho, derechos Humanos, multiculturalismo, población indígena.

\begin{abstract}
The present article states that the "universality" of Rights comes into an ontological contradiction when put in front of its legal figure; whereas, on one side, is pursued that all people access the same "Rights" in a homogeneous way, and, on the other hand, it is not recognized the heterogeneity of cultural varieties among communities. To defend such statement is used as theoretical reference the approach of Foucault $(1998,1999)$ and Galtung (1969) regarding the exertion of domination and structural aggression that has come due to globalization. Is taken as case of study the Indigenous Reserve of San Lorenzo (Resguardo San Lorenzo) located in the Municipality of Supía, in the Caldas Department of the Colombian Andean area. Therefore, at first, is analyzed the stance of the Human Rights Universality, and, specially, about the Rights of indigenous people; in second place, is analyzed the idea of universality of rights, having as case of study, the indigenous Reserve of San lorenzo and; in third place, come to the conclusion that, despite the universality of rights attempts directly against the hereditary of the indigenous people, those have come developing community strategies to guarantee the multicultural prevalence of the people.
\end{abstract}

Key words: Human Rights, Multiculturalism, Indigenous people.

\title{
Introducción
}

En un momento histórico en el que las comunidades minoritarias son sometidas en detrimento de sus prácticas y territorios por instituciones internacionales y nacionales que imponen su visión con la bandera de sociedades "civilizadas" y "globalizadas", se hace necesario empezar a pensar las implicaciones culturales que todos estos movimientos de masas e incluso homogenizantes han generado. El número de dialectos existentes a nivel mundial va en disminución; los territorios ancestrales han sido desbastados a favor de las empresas extractivas, las prácticas ancestrales dejaron de ser lo que otrora, para convertirse en exhibiciones turísticas; la alienación cultural está acabando con el patrimonio inmaterial y material de las comunidades nativas. Todo esto con la idea de la globalización y de la universalización. ¿Ahora, globalización y universalización de qué? ¿Qué tan válido es imponer la visión de unos pocos frente a la multiplicidad de perspectivas culturales y étnicas con las que goza nuestro territorio?

Al respecto Galtung (1969), plantea la noción de violencia estructural como el resultado de las diferentes acciones que de una u otra manera influyen en la pérdida de identidad, bienestar, libertad, además de las diferentes necesidades insatisfechas de los pueblos que contribuyen con el deterioro de sus condiciones de vida o supervivencia. Desde esta perspectiva son dos tipologías de necesidades básicas que todo Estado debe proteger para garantizar la pervivencia de las comunidades. Al respecto Galtung (1969) plantea las necesidades básicas 
materiales y las necesidades básicas inmateriales. A las primeras pertenecen la alimentación, la educación, la vivienda, el estudio, la salud y el vestido. A las segundas, la identidad y la libertad. Los conflictos en las comunidades aparecen cuando estas necesidades son violentadas generando una brecha entre las condiciones de acceso que deberían tener y las condiciones que realmente tienen.

Al realizar un paralelismo entre lo planteado por Galtung (1969) y lo evidenciado en las vivencias cotidianas de los pueblos indígenas latinoamericanos encontramos que todas aquellas necesidades no se colman, y ello ocurre, porque los gobiernos enfocan sus iniciativas políticas en suplir los requerimientos humanos desde las masas, lo que demuestra una clara vulneración a los derechos fundamentales de los pueblos indígenas, y el connatural peligro de su aniquilación total.

A este respecto bien vale la pena recordar que todo proceso de dominación implica necesariamente un aniquilamiento de lo particular, esto es, despersonalizar al individuo para convertirlo en un colectivo que deja de pensarse para asumirse desde lo que se espera que haga. Tal cómo lo advirtió Foucault (1999):

[...] cuanto más libre es la gente y más libres son unos en relación a los otros, mayores son los deseos en unos y en otros de determinar la conducta de los demás. Cuanto más abierto es el juego más atractivo y fascinante resulta' (Foucault. 1999: 415)

En este sentido, se podría pensar que la violencia es la versión más primitiva del ejercicio de dominación. Entre más sofisticada sea la forma de dominación menos perceptible es la vulneración de derechos a la que se somete al pueblo. Según Foucault (1998) se está ante un estado de dominación cuando el ejercicio de la violencia es permanente y unidireccional.

La propuesta del panóptico de Jeremy Bentham, presentada por Foucault para explicitar cómo los procesos desarrollados durante la edad media fomentaban la dominación a través de la disciplina, evidencia cómo paulatinamente la dominación se fue acoplando a diferentes dispositivos de poder que hicieron posible que, quién sea sometido no se vea a sí mismo enfrentado a una relación de subordinación. No portar el uniforme que corresponde, salir de las filas antes de tiempo, no usar los artículos de moda, entre otros aspectos, hacen que los grupos humanos se controlen a sí mismos y ejerzan dominio sobre sus actuaciones. En este sentido, no seguir a las mayorías es desobedecer la indicación general.

Ser indígena, llevar un atuendo por fuera de la moda del momento, tener otras prácticas culturales, ver el mundo desde otra lengua, actuar conforme a cosmologías diferentes y ser desplazado de sus territorios ancestrales, ha devenido en el primer motivante para que las poblaciones vulnerables se vean forzadas a imitar a las mayorías en aras de un proceso de aceptación. Acciones que a través del tiempo solo han dejado una gran pérdida patrimonial para cada uno de los pueblos y para la humanidad. En palabras de Giménez (2005):

La idea que subyace en el multiculturalismo es la necesidad de reconocer las diferencias y las identidades culturales. Es la primera expresión del pluralismo cultural que promueve la 
no discriminación por razones de raza o de la diferencia cultural, así como el derecho a ello. (Giménez, 2005: 21)

En este sentido, las políticas públicas nacionales y trasnacionales que afecten de algún modo a los pueblos indígenas deben elaborarse a la luz de la multiculturalidad de las minorías étnicas que permanecen en el territorio, en congruencia con la multiplicidad de culturas que coexisten en la sociedad para no generar desequilibrio entre los actores territoriales como lo afirma Walsh (2005):

En este contexto la tolerancia del otro, es considerada central, valor y actitud suficiente para asegurar que la sociedad funcione sin mayor conflicto. Pero además de obviar la dimensión racional, esta atención a la tolerancia como eje de la problemática multicultural oculta la permanencia de las desigualdades sociales, así que deja intactas las estructuras y las instituciones que privilegian unos sobre otros. (p.45)

Escobar (2008) afirma precisamente cómo las acciones estatales globalizadoras enmarcadas en políticas neoliberales a partir de la segunda mitad del siglo XX generaron grandes afectaciones en las dinámicas de apropiación espacial de los grupos étnicos en Colombia acelerando la destrucción de procesos identitarios arraigados al lugar; debilitando el sentido de pertenecía hacia los elementos naturales que eran concebidos como espacios vitales de interacción social en los cuales las comunidades encontraban oportunidades para generar desarrollo local y regional.

En un país como Colombia en donde su diversidad cultural es amplia, la multiculturalidad debe ser concebida como herramienta política fundamental para garantizar bienestar y protección a las comunidades indígenas que resignifican el territorio desde su ancestralidad enmarcada en su cosmovisión, sus tradiciones y sus múltiples maneras de producir el espacio para el buen vivir; no obstante; dichas determinaciones se han enmarcado en parámetros internacionales que en gran medida han representado una amenaza homogeneizadora y trasgresora para la particularidad de cada una de estas comunidades. En este sentido, la multiculturalidad debe ser comprendida desde un enfoque social, pero también desde lo jurídico, para garantizar los derechos fundamentales a los pueblos indígenas y la identidad de cada uno de sus integrantes.

Las sociedades globalizadas pasan por alto el hecho de que los procesos identitarios propios del ser humano y de las colectividades en las que interactúan están condicionados por procesos internos y externos a nivel intra e intercolectiva que posibilitan su evolución (Fleck, 1979, 1986). La identidad cultural no solo es generada por procesos internos a las dinámicas sociohistóricas y culturales de un colectivo, sino que también pueden ser el producto de asociaciones con prácticas, historias y dinámicas socioculturales ajenas que con el pasar del tiempo son tomadas como propias. Priorizar las prácticas intercolectivas en detrimento de las intracolectivas implica en términos de Galtung (1969) una forma de violencia estructural o, en términos fleckeanos, un estancamiento del proceso socio histórico de la cultura.

Los procesos de enajenación cultural, violación de derechos fundamentales y perdida territorial como consecuencia del conflicto armado, atentan contra la integridad y pervivencia de los 
pueblos indígenas de Colombia, esto es, contra el patrimonio cultural material e inmaterial que históricamente han representado estos pueblos. Uno de los problemas que enfrentan las comunidades indígenas consiste en que, pese a que con la Constitución Política de 1991 se les reconoce como comunidades autónomas a nivel sociocultural y político, no existe claridad respecto a la conformación jurídica de sus territorios, sumado a una ausencia de políticas públicas que contribuyan estructuralmente con su pervivencia y buen vivir.

Siguiendo a Falcon (2016) podríamos resumir estos planteamientos en los siguientes aspectos:

1) se reconoce la importancia de la cultura grupal o particular en la construcción de la identidad de los individuos; 2) se acepta la posibilidad de que los individuos de grupos culturales o étnicos tengan un reconocimiento expreso de sus particularidades de forma normativa, posibilitando la protección de éstos frente a las injerencias de la cultura mayoritaria; 3) se refuerza todo el aparato normativo e institucional antidiscriminatorio hacia los individuos de los grupos étnicos o culturales desaventajados. (p.6)

Si bien, la Declaración Universal de los Derechos Humanos, de aquí en adelante DUDH, fue un documento elaborado en 1948, aún tienen vigencia y es aceptado a nivel internacional, las implicaciones sociales, jurídicas y culturales de la DUDH han llegado a niveles inimaginables en la medida en que, si bien vela por el bien común, el hecho de que intente homogenizar los derechos termina convirtiéndose en una contradicción ontológica, en tanto, la universalización atenta con la particularidad intercultural de los pueblos, tal como se evidenciará en el presente estudio.

En lo que sigue se analiza de manera sistemática el documento DUDH, en correlación con la Declaración Universal de los Pueblos indígenas, de aquí en adelante DUDPI. Se sostiene la tesis de que su carácter homogeneizador ha vulnerado durante años la multiculturalidad de los pueblos sometiéndolos a graves abusos y violaciones de múltiples derechos humanos tal como es el caso específico del Resguardo San Lorenzo.

Con la DUDH no se puso un fin a la vulneración de los derechos humanos en el orden mundial. No obstante, se implementó como parámetro, por parte de los Estados, para el diseño de políticas y acciones en pro de la defensa de los derechos de las personas consagrándose como principios rectores del actuar de las comunidades para lo cual la DUDH establece una serie de principios en los que se proclaman unas determinaciones que cobijan al ser humano en general.

El artículo No 2 de la DUDH expresa que: "Toda persona tiene todos los derechos y libertades proclamados en esta Declaración, sin distinción alguna de raza, color, sexo, idioma, religión, opinión política o de cualquier otra índole, origen nacional o social, posición económica, nacimiento o cualquier otra condición". (6). Ello implica que la visión general prima por sobre la particularidad o, en otras palabras, que los pueblos indígenas deben ser homogenizados conforme a las demandas de la globalización.

En el análisis del documento de la DUDH claramente no se menciona distinción alguna de los derechos humanos para con los pueblos indígenas; cada uno de los artículos se expresa en 
general a los seres humanos, aniquilando las diferencias que yacen en la multiculturalidad de cada pueblo, tal como lo afirma Falcón (2016):

[...] Se da un salto en el hecho de que la justicia social pueda ser definida en términos de reglas que no hagan caso omiso de las diferencias, se acepta que puedan ser desiguales. De igual forma, se invierte la carga de la prueba, la que ya no corresponde a quienes defienden los derechos de las minorías, sino a quienes plantean que las reglas no deben hacer caso de las diferencias, debiendo probar que el statu quo no crea injusticias para los grupos culturales o étnicos desaventajados. (p.7)

La DUDH se analiza en función de las categorías específicas del proyecto "Entidades Territoriales Indígenas: Derechos Humanos, Gobernabilidad y Políticas Públicas en la Ecorregión Cafetera. Fase II". Las cuales giran en torno a la vulneración de derechos en agua potable, educación, salud, y acceso a la tierra. Analizando cada uno de los artículos de la DUDH se pone en evidencia un hallazgo importante y es que el planteamiento respecto a los derechos se hace a nivel general ${ }^{1}$, es decir, no hace énfasis específico en minorías étnicas, tal como se muestra en el artículo 22 cuando expresa :

Toda persona, como miembro de la sociedad, tiene derecho a la seguridad social, y a obtener, mediante el esfuerzo nacional y la cooperación internacional, habida cuenta de la organización y los recursos de cada Estado, la satisfacción de los derechos económicos, sociales y culturales, indispensables a su dignidad y al libre desarrollo de su personalidad. (p.46)

Es claro que existen unas garantías generales de derechos humanos, pero no se contextualizan puntos específicos, de tal forma que los Estados se encuentran en plena libertad de proteger los derechos que su estructura política le permita; para el caso colombiano la Constitución política de Colombia de 1991 en su artículo 1 proclama:

Colombia es un Estado social de derecho organizado en forma de republica unitaria, descentralizada, con autonomía de sus entidades territoriales, democrática, participativa y pluralista fundada en el respeto de la dignidad humana, en el trabajo y la solidaridad de las personas que la integran y en la prevalencia del interés general. (p.17)

El Estado colombiano, proclamado con la constitución de 1991 como un Estado social de derecho, está en el deber de satisfacer las necesidades básicas a los habitantes del territorio, debe garantizar el acceso a los servicios de salud, educación, tenencia de tierras y agua potable, entre otros derechos, a todas las comunidades que habitan el territorio nacional. La DUDH, le adjudica la potestad y cumplimiento sobre los derechos de los pueblos a los Estados. No obstante, en Colombia durante los últimos 50 años los episodios de violencia y corrupción han evidenciado que el interés particular prima sobre el general, esto es, la mayor parte de la población que, a su vez, es la más vulnerable. Entre dichas comunidades vulnerables

1. Si bien no se desconoce que la Declaración Universal de los Derechos Humanos fue pensada y elaborada en el contexto de la segunda guerra mundial y que su objetivo fue principalmente proteger los derechos y propender por el bienestar del ser humano, es claro que su carácter homogeneizador excluyo completamente la multiculturalidad existente las minorías en el mundo; esto finalmente sitúa dicho documento en una postura contraproducente ya que ha fortalecido desde su carácter totalizador la vulneración de múltiples derechos humanos. 
contamos las comunidades indígenas en las que se centra el proceso investigativo del cual el presente artículo da cuenta, en especial el resguardo indígena de San Lorenzo.

En la DUDH no se hacen distinciones culturales, raciales, étnicas, políticas o incluso territoriales, lo que implica que los pueblos indígenas, aunque han permanecido ancestralmente en el territorio, a escala mundial deben ser considerados con igualdad dentro de sus particularidades. En un país como Colombia lo anterior ha generado grandes afectaciones a las minorías, teniendo en cuenta que el reconocimiento de sus derechos y de su multiculturalidad fueron plasmados en la Constitución Política de 1991, anterior a ello, los pueblos se encontraban en total indefensión siendo víctimas de violaciones graves de derechos humanos de toda índole.

En la revisión de la Constitución Política de 1886, que fue la carta de derechos del país durante más de un siglo, no se encontró ningún artículo referido a los resguardos indígenas; en el título III de los derechos civiles y las garantías sociales, lo único referente a la "protección de minorías" se especifica en el artículo 22 el cual enfatiza en la abolición de la esclavitud, es decir, para la época las comunidades indígenas no poseían legalmente sus territorios ancestrales. Desde la elaboración de la Constitución Política de 1886, hasta la actualidad permanece un vacío jurídico frente al tema, consecuencia de ello son las múltiples violaciones a derechos en los pueblos indígenas de Colombia, especialmente, por el conflicto armado, narcotráfico y la violencia social presente en el país finalizando el siglo XX y parte del actual.

Lo anterior se argumenta desde el escrito de José Silvio Tapasco (2016) indígena perteneciente al pueblo de los Embera Chami específicamente al resguardo San Lorenzo, el cual afirma:

Los actores armados legales y al margen de la ley han sembrado el terror en nuestras comunidades, han asesinado, desaparecido, torturado, masacrado, estigmatizado y señalado a nuestra gente, han establecido el bloqueo de alimentos y medicamentos, han utilizado a los Embera como escudos humanos, se han restringido libertades fundamentales de tránsito y locomoción, han reclutado a nuestros jóvenes, han violado e irrespetado a nuestras mujeres indígenas y amenazan con la muerte si se atreven a denunciar los atropellos. Estos grupos quieren imponer su autoridad y ejercer control social en nuestros territorios, profanar nuestros sitios sagrados y pisar nuestros maestros y jaibanas, han convertido nuestros territorios en escenarios de guerra, en laboratorios de producción de cultivos de uso ilícito, en centros de bases militares y batallones de alta montaña, y los cultivos de pan coger han sido arrasados por las fumigaciones aéreas. (p.30)

Todos los acontecimientos narrados anteriormente fueron de total conocimiento para el Estado colombiano que hasta la actualidad se ha pronunciado poco o nada como garante de la protección y conservación de los pueblos indígenas como patrimonio de la humanidad. El resguardo indígena San Lorenzo como bien lo afirma José Silvio Tapasco (2016) ha sufrido de violaciones múltiples a la vida, al territorio, a la cultura, a la lengua materna, a la autonomía, al gobierno propio; así como el acceso a los sitios sagrados, despliegue de las creencias y cosmovisión propia, acceso a la salud y educación y, por último, a los recursos naturales. 
La Conferencia General de la Organización Internacional del Trabajo (OIT) adoptó en 1989 el Convenio 169 sobre pueblos indígenas y tribales en países independientes, reconocido actualmente como el principal instrumento internacional sobre derechos de los pueblos indígenas, y ratificado en Colombia por la Ley 21 de 1991. El Convenio reconoce los derechos tanto individuales como colectivos de los miembros de los pueblos indígenas y hace énfasis en el reconocimiento y la protección de sus costumbres, tradiciones, instituciones y prácticas, en el derecho a decidir sobre su desarrollo económico, social y cultural, en el derecho a la propiedad y posesión del territorio tradicional y a la administración y protección de sus recursos naturales, a la consulta previa, a un servicio de salud adecuado que tenga en cuenta sus prácticas curativas y medicamentos tradicionales, a la igualdad en el acceso a la educación y a una formación profesional pertinente.

Este convenio sirvió como precedente para la Declaración de las Naciones Unidas sobre los derechos de los pueblos indígenas de 2007. El cual carece de fuerza jurídica obligatoria, pero traza el rumbo de las normas jurídicas internacionales en esta materia.

En 1991 la Asamblea Nacional Constituyente decretó en el artículo $7^{\circ}$ de la Constitución Política: "El Estado reconoce y protege la diversidad étnica y cultural de la nación colombiana" y en el artículo $8^{\circ}$ : "Es obligación del Estado y de las personas proteger las riquezas culturales y naturales de la nación". Con respecto a la organización territorial del país, el artículo 286 de la Constitución Política establece los territorios indígenas como entidades territoriales las cuales: "Gozan de autonomía para la gestión de sus intereses, dentro de los límites de la Constitución y la ley" (artículo 287). Es decir, les confiere la potestad para administrar sus recursos, para decidir su plan de desarrollo económico, social y cultural, y para regirse de acuerdo con sus costumbres, tradiciones y gobierno propio, entre otros (artículo 330).

La expedición de la Ley Orgánica de Ordenamiento Territorial o Ley 1454, necesaria para la creación de las entidades territoriales indígenas, se realizó en 2011, pero se limitó a ordenar en su artículo 37 la creación de un proyecto de ley especial para la creación de dichas entidades; no obstante, esta ley fue demandada por no cumplir, entre otros, el mandato del artículo 329 de la Constitución Política.

El Plan Nacional de Desarrollo 2014-2018 “Todos por un nuevo país”, expedido por la Ley 1753 de 2015, en el artículo 117, establece la adopción, previa consulta y concertación, de una política pública para la protección de derechos de las familias, mujeres, niñas y niños, jóvenes y mayores indígenas. También acuerda el diseño, coordinación, articulación y seguimiento de la política para la prevención del reclutamiento, utilización y violencia sexual contra niños, niñas y adolescentes por grupos armados al margen de la ley y por grupos de delincuencia organizada, incorporando a su vez, un enfoque diferencial étnico para los pueblos indígenas (artículo 123). En el artículo 232 establece la formulación de la política pública integral de mujer con el enfoque étnico, etario y territorial (...) (Plan Nacional de Desarrollo, 2014). Este mismo año mediante el Decreto 1953, se creó un régimen especial con el fin de poner en funcionamiento los territorios indígenas respecto de la administración de los sistemas propios de los pueblos indígenas hasta tanto se expida desde el Congreso la ley propuesta en el artículo 329 de la Constitución Política donde se establece en el artículo $1^{\circ}$ que tiene como objeto “(...) el 
fortalecimiento de la jurisdicción especial indígena; con el fin de proteger, reconocer, respetar y garantizar el ejercicio y goce de los derechos fundamentales de los Pueblos Indígenas (...)"

En razón a lo anterior, es evidente que durante los últimos 27 años el Estado colombiano ha dirigido esfuerzos hacia el reconocimiento y respeto por los derechos de los pueblos indígenas mediante la expedición de decretos, leyes, propuestas y acuerdos que desafortunadamente no se aplican en la práctica o avanzan de forma pausada debido a la suma de varias circunstancias. En 2017 La Corte Constitucional en el Auto 266 realizó la evaluación de los avances, rezagos y retrocesos en la superación del Estado de Cosas Inconstitucional (ECI) declarado mediante la sentencia T-025 de 2004, y puso de manifiesto que no existen indicadores y sistemas de información integrales que permitan evidenciar y hacer seguimiento y detectar errores que permitan adoptar decisiones encaminadas a contrarrestar la vulnerabilidad de las comunidades. También advierte sobre la dificultad para acceder a la información debida a los trámites requeridos para ello y a la falta de disponibilidad en línea. Sin embargo, en el mismo documento señaló la adopción de otras fuentes de información como la contenida en los informes de la ACNUR, y es precisamente esta fuente junto al material entregado por la Defensoría del Pueblo, la que advierte de la condición de vulnerabilidad y riesgo de desaparición material e inmaterial de estas comunidades, lo que hace inminente el desarrollo del presente estudio.

En Latinoamérica son significativas las investigaciones realizadas en términos de las situaciones que obstaculizan y/o limitan el acceso a los derechos fundamentales como la educación, la salud, la nutrición, agua potable y tenencia de la tierra en las comunidades indígenas a lo largo y ancho del territorio; es así como frente al tema de educación está el trabajo de Molina (2012), donde alude que tiende a ser un sueño lograrlo, por cuanto en los territorios indígenas estos no cuentan con la autonomía de administrar libremente sus recursos, pese a los avances que se han realizado en el país para incluir a las comunidades en las decisiones que competen, frente a la administración de sus tierras, respeto de una cultura propia, justicia autóctona, entre otros. Desafortunadamente, estos al no estar constituidos de manera sólida, no cuentan con las mismas competencias que la ley (Ley 715 de 2001) les brinda a todos los entes territoriales, caso particular el del autogobierno para decidir sobre sus destinos.

Se encuentra que la tasa de alfabetismo en los grupos indígenas alcanza el $71,4 \%$ (74,1\% de los hombres y $68,6 \%$ de las mujeres), lo que es inferior a los demás grupos étnicos y se queda en los niveles de educación básica primaria. Muchos de los resguardos a nivel nacional practican la etnoeducación ${ }^{2}$, que les permite la integración de su cultura al resto de la sociedad. (Molina, 2012: 272)

Por ello, si bien es cierto los adelantos en el reconocimiento constitucional de su identidad y la inclusión dentro de los organismos políticos y administrativos del Estado, la autonomía con la que cuentan algunos pueblos indígenas colombianos no se encuentra sino en el papel de la

2. Ley 115 de 1994 encuadra esta educación en su artículo 55, y la define como aquella que se ofrece a grupos o comunidades que integran la nacionalidad y que poseen una cultura, una lengua, unas tradiciones y unos fueros propios y autóctonos. Esta educación debe estar ligada al ambiente, al proceso productivo, al proceso social y cultural, con el debido respeto de sus creencias y tradiciones. 
normatividad, la discusión está en que hace falta mucha voluntad política para que se realicen las reformas institucionales, económicas, políticas y judiciales que favorezcan la autonomía de estos pueblos. Igualmente, el foco de la discusión está en “(...) el tema de la autodeterminación como pueblo y el alcance que esta pueda tener al momento de decidir tener un sistema educativo propio que no tenga ninguna relación con el sistema educativo nacional (...)". (Molina, 2012: 290).

En la investigación de Amoroz (2011), donde a través de un estudio empírico se muestra la grave situación de salud que viven en la actualidad los pueblos originarios ante un sistema de salud cada vez más deficiente e ineficaz, en México. Asimismo, comenta las posibilidades de la existencia de mecanismos que hagan exigible y justiciable el derecho a la salud por parte de la población y del Estado, y las demandas y alternativas que se han escuchado desde los pueblos, particularmente en relación con la salud donde los derechos fundamentales para ser efectivos tienen que adquirir un sentido más operacional para la gente y cuyo reto es político.

En esta misma línea, se ubica el trabajo de Ríos, Álvarez,Corrales y Escobar (2002), donde argumentan que las comunidades objeto de análisis presentan una situación de salud precaria, que se relaciona con las irregulares condiciones sanitarias de sus viviendas y economías de subsistencia, sumado al alto índice de enfermedades como infecciones respiratorias, diarreicas y de la piel que presenta su población. No obstante, el estudio también revela que los nasas han venido identificando diferentes estrategias curativas desde sus prácticas ancestrales que no solo contribuyen con los servicios de salud que brindan desde su red propia, sino que también reflejan su identidad y sincretismo.

Bidaseca (2007) analiza los "procesos culturales silenciados"; es decir, aquellos mecanismos históricos de exclusión culturales, institucionales, económicos y políticos -formales e informales- de la/os campesina/os e indígenas sobre el derecho a la tierra/territorio. Encuentra que una de las variadas formas que adquiere la exclusión, como mecanismo que define la dominación, en el mundo rural, es negar u obstaculizar a los sujetos (con tenencia precaria de la tierra, a la/os arrendataria/os o a aquellos cuya posesión esté amenazada) el derecho a la tierra.

Las anteriores investigaciones dan cuenta del panorama histórico y actual que han vivido las comunidades indígenas en cuanto a las condiciones de acceso a los derechos fundamentales. De esta manera, no se puede desconocer que el acceso a los derechos por parte de estas comunidades en nuestro territorio colombiano, guarda una estrecha relación con los procesos de gobernabilidad; en tanto las condiciones para la gobernabilidad desde las distintas voces indígenas, pasan por la concreción de un "gobierno propio" bajo los parámetros de una autonomía integral. Sin embargo, el proceso abierto por la constitución, reconociendo el carácter multiétnico y pluricultural de la nación, ha implementado mecanismos de integración, antes que proveer mecanismos reales de autonomía. Dicha ambigüedad se expresa en la multiplicidad de acciones que se desarrollan en el panorama actual, y que constituyen los puntos de encuentro del movimiento indígena desde una perspectiva nacional. 
En este entramado de intereses y procesos, los indígenas reclaman su autonomía. Un gobierno propio, que significa el pleno reconocimiento de los cabildos y las comunidades para controlar, vigilar y organizar su vida en los resguardos. Este reconocimiento significa también la posibilidad de decidir y negociar sobre su forma de participación en las políticas que les son propuestas.

Pasados más de 50 años de promulgada la DHDH y de vulneración de derechos para los pueblos indígenas y minorías, Naciones Unidas elaboró la DUDPI aprobada para el año 2007, en la cual se establecen artículos que fungen como principios rectores en temas de derechos humanos que cobijan todos los pueblos indígenas a nivel mundial, teniendo en cuenta los múltiples abusos a los que han sido sometidos históricamente, como es el caso del resguardo San Lorenzo.

En la nueva declaración se realiza abiertamente un reconocimiento diferencial para los pueblos indígenas, en esta se estipula su multiculturalidad, su derecho a la diferencia y ser respetados como tal, se enfatiza la importancia de su presencia como patrimonio cultural de la humanidad, por su diversidad y su presencia histórica en el mundo. Además, manifiesta su preocupación por su discriminación y las injusticas históricas, como el desplazamiento de sus territorios ocupados incluso antes de los procesos de colonización.

A pesar de la libre determinación de los pueblos indígenas en materia económica, social, cultural y política proclamada en la DUDPI, muchos de los elementos fundamentales para su libre desarrollo están a cargo del Estado, quien juega un papel determinante en todo lo correspondiente al reconocimiento, protección y promoción de dichos pueblos, tal como se expresa en el artículo 8:

1. Los pueblos y los individuos indígenas tienen derecho a no ser sometidos a una asimilación forzada ni a la destrucción de su cultura.

2. Los Estados establecerán mecanismos eficaces para la prevención y el resarcimiento de:

a) Todo acto que tenga por objeto o consecuencia privarlos de su integridad como pueblos distintos o de sus valores culturales o su identidad étnica;

b) Todo acto que tenga por objeto o consecuencia desposeerlos de sus tierras, territorios o recursos;

c) Toda forma de traslado forzado de población que tenga por objeto o consecuencia la violación o el menoscabo de cualquiera de sus derechos;

d) Toda forma de asimilación o integración forzada;

e) Toda forma de propaganda que tenga como fin promover o incitar a la discriminación racial o étnica dirigida contra ellos. 
Es claro que los Estados deben implementar políticas públicas que protejan a los pueblos indígenas que yacen al interior de sus territorios, como patrimonio cultural de la humanidad, respetando las diferenciaciones y particularidades que tiene cada pueblo en cada región y de las diversas tradiciones históricas y culturales. El artículo 11, expresa directamente que con medidas estatales se deben establecer mecanismos eficaces que propendan por la restitución de bienes culturales, intelectuales, religiosos e incluso espirituales que hayan sido vulnerados sin su consentimiento libre e informado.

De tal forma sobre el Estado reposa una amplia responsabilidad frente a los pueblos indígenas, según lo expresa la DUDPI. A pesar de lo expuesto, evidentemente dichas disposiciones no se cumplen a cabalidad, si bien, los pueblos indígenas del mundo se encuentran en peligro de extinción, para el caso colombiano no se visualizan acciones estatales que propendan por su protección.

La Organización de Naciones Unidas (ONU) conformada por 192 países del mundo que se reúnen para trabajar a favor de la paz y seguridad de los pueblos, luego de más de 20 años desde la creación del Grupo de Trabajo sobre las Poblaciones Indígenas, el 13 de septiembre de 2007 la ONU adoptó la Declaración sobre los Derechos de los Pueblos Indígenas (DDPI o por sus siglas en inglés UNDRIP). Se debe tener en cuenta que, en el presente caso, la declaración no tiene rango de tratado internacional jurídicamente obligatorio, es un documento declarativo u orientativo. El valor de la d de estaconsiste en que es un documento que reviste compromisos de orden político, ético y moral; pero no genera obligaciones más allá que la buena voluntad de adopción en el sistema jurídico interno de las naciones los postulados de este documento. No obstante, puede usarse como instrumento guía para proyectos de leyes, políticas públicas y enfocar las decisiones judiciales sobre asuntos indígenas. En países como Argentina, Ecuador y Bolivia, hacen parte de sus textos constitucionales.

Como se evidencia, no solamente en el nivel local colombiano, existe desidia y falta de interés en los asuntos relacionados con las comunidades indígenas. La falta de preocupación de varios países acerca de los proyectos de autodeterminación y control de recursos naturales en las tierras ancestrales indígenas, han hecho que las discusiones y análisis sobre los elementos fundamentales para el reconocimiento de los derechos de los indígenas, no hayan fluido de manera adecuada. Por ejemplo, al momento de llevarse a cabo la votación sobre la procedibilidad de la declaración cuatro países que ancestralmente tienen raíces y comunidades indígenas activas, votaron en contra. Ellos fueron Estados Unidos, Canadá, Australia y Nueva Zelanda. Debe aclararse que posteriormente estas naciones revirtieron su postura, pero este dato, es un elemento indicativo de la falta de interés que los asuntos indígenas revisten a nivel global, de lo cual como se dijo, no se escapa nuestro país.

Para el caso específico del resguardo indígena San Lorenzo, en la sentencia T-025 del 2018, se exponen todos y cada uno de los derechos vulnerados individual y colectivamente en sus comunidades tanto por parte del Estado colombiano como por grupos al margen de la ley con presencia en el territorio desde finales del siglo XX. La sentencia 025 manifiesta abiertamente que las reivindicaciones obligatorias por parte del Estado deben atender a: 
Despojos administrativos, asesinatos, desplazamiento forzado y consecuente abandono de sus usos y costumbres dentro de su territorio ancestral ubicado entre los municipios de Riosucio y Supía en el departamento de Caldas en razón a la confrontación armada y constantes tomas guerrilleras perpetradas en la zona por las Farc, Los Grupos paramilitares y las fuerzas armadas de Colombia; siendo los causantes de la afectación al territorio colectivo encontrándose dentro del término establecido en la Ley. (p.3)

La vulneración de los derechos humanos en el resguardo indígena San Lorenzo, se agudizó en la década de 1980; la toma del país por el narcotráfico y grupos armados al margen de la ley fueron solo algunos de los factores que pusieron en riesgo total la supervivencia de los pueblos indígenas; a la luz de múltiples violaciones que se exponen en la sentencia 025 del 2014, el Estado colombiano desde finales del siglo anterior no se ha pronunciado al respecto, y como garante de los derechos de los pueblos indígenas como se expresa en la DUDPI, ha permitido la extinción paulatina de las comunidades indígenas en la ausencia de una política que incluya un enfoque diferencial de diversidad étnica y cultural que proteja a los indígenas desplazados, vulnerados o en peligro de desplazamiento.

La Corte Constitucional de Colombia en consonancia con la sentencia T-025 del 2004 que plantea las condiciones para que las asociaciones de desplazados interpongan acciones dadas las condiciones de vulnerabilidad de población desplazada, y por el hecho de que en su mayoría son minorías especiales protegidas por la ley como los adultos de la tercera edad, madres cabeza de hogar y las poblaciones étnicas, expiden el Auto 004 del 2009 con el cual se realiza directamente una reiteración al Estado de su papel fundamental en la protección de las minorías como se consagra en las DUDH y la DUDPI, y su inacción en la defensa de los pueblos indígenas como patrimonio cultural de la humanidad.

El Estado colombiano no ha reconocido en términos reales la situación de vulnerabilidad de los pueblos indígenas. Con el auto 004 del 2009 la Corte Constitucional argumenta que la situación respecto a la vulneración de derechos con los pueblos indígenas es grave e invisible, puesto que las instituciones, que en su momento eran las encargadas de la protección y preservación de sus derechos, no se manifestaron ni tomaron medidas sobre el asunto:

Los grupos indígenas colombianos están particularmente indefensos y expuestos al conflicto armado y sus consecuencias, particularmente al desplazamiento. Deben soportar los peligros inherentes a la confrontación sobre la base de situaciones estructurales preexistentes de pobreza extrema abandono institucional que operan como factores, catalizadores de las profundas violaciones de derechos humanos individuales y colectivos que ha representado para ellos la penetración del conflicto armado en sus territorios. (p.4)

Las disposiciones del Estado con el Auto 004 del 2009 fue en principio reiterar la responsabilidad de las instituciones para velar y acelerar el proceso de restablecimiento de derechos de las minorías afectadas por el conflicto armado, entre ellos los pueblos indígenas; el llamado se centró en la implementación de programas y proyectos que impulsaran la prevención de fenómenos sociales como el desplazamiento forzado, con políticas de enfoque diferencial para las comunidades indígenas, cumpliendo con el principio de la diversidad etnocultural. En el cumplimiento de esta orden el director de la otrora Acción Social y al 
ministro del Interior y de Justicia, con la participación de la Directora del ICBF, la Ministra de Educación, el Ministro de la Protección Social, el Ministro de Defensa y el Director del Programa de Acción Integral contra las Minas Antipersonal ${ }^{3} y$ en conjunto con la participación legitima de los pueblos indígenas iniciarían la construcción de planes de salvaguarda étnica del conflicto armado.

Como lo estipula la DUDH y DUDPI el Estado como garante y protector de los derechos de los pueblos indígenas, en su agenda de gobierno debe ser prioritaria la atención a poblaciones vulnerables; el Auto 004 del 2009 es un llamado de atención a la inacción de políticas estatales que propendan por el bienestar de las minorías a las cuales les fueron violados sus derechos fundamentales, tal como es el caso específico del resguardo indígena San Lorenzo.

En la actualidad no solamente el resguardo indígena San Lorenzo se encuentra al borde de su exterminio, en su mayoría los pueblos indígenas en Colombia se desangran lentamente por políticas globalizadoras y neoliberales que históricamente han transgredido la ancestralidad y su derecho a la protección como patrimonio cultural de la humanidad. La DUDH y la DUDPI son modelos de carácter internacional establecidos como referentes en derechos humanos que evidentemente en Colombia no se cumplen al imponer al Estado como máxima autoridad protectora y garante en materia de derechos humanos especialmente en los pueblos indígenas.

Con el Auto 004 del 2009 y la sentencia 025 del 2014 se reafirma la débil gestión del Estado colombiano en su labor encomendada por la DUDPI; las reiteraciones de la Corte Constitucional frente a la reivindicación de los derechos de los pueblos indígenas, muestran en un primer momento, las precarias situaciones a las que han sido sometidas las comunidades; en un segundo momento, la obligación de las instituciones para proteger, conservar, y propender por los derechos de las minorías étnicas, en su incipiente gestión de políticas públicas con enfoque diferencial.

La DUDH y la DUDPI y sus planteamientos frente a la universalidad de los derechos humanos, fracasan en su aplicación desde los Estados; la transgresión a la heterogeneidad y a la multiculturalidad de los pueblos indígenas será un común denominador desde que prevalezca el interés general sobre el particular, por lo cual es herrado establecer unos principios rectores que cobijen a las minorías éticas a nivel internacional si desde el territorio en el que habitan no existe una cultura de respeto y protección a sus prácticas ancestrales y a su cosmovisión de la vida.

Concluyendo con el análisis de la DUDH Y DUDPI en función de la identificación en la aplicación de los derechos humanos especialmente en los pueblos indígenas, se evidencia lo planteado por Galtung (1969) respecto a la violencia estructural. La ineficiencia del Estado colombiano para cumplir con sus obligaciones como Estado Social de Derecho. Los abusos históricos narrados por los habitantes del resguardo indígena San Lorenzo, aunados al auto 004 del 2009 y a la sentencia T-025 del 2018, demuestran la hipótesis planteada en torno a la homogenización y aniquilación, en el sentido de la crítica foucaultiana, de los pueblos

3. Instituciones mencionadas en el Auto 004 del 2009 
indígenas desde los planteamientos universales de la DUDH y el nombramiento del Estado como ente supremo para velar por la protección de las minorías étnicas y su conservación en el territorio como se estipula en la DUDPI.

En el contexto actual de implementación del Acuerdo Final para la Construcción de una Paz Estable y Duradero, no debemos dejar de lado, que si bien el Acuerdo contempla componentes importantes de reivindicación de derechos de las poblaciones más vulnerables -campesinos y afros-, este documento no fue exactamente escrito pensando en las comunidades indígenas. Se entiende que el acuerdo haya sido redactado en clave de derechos de las poblaciones campesinas, toda vez que la génesis del conflicto se encuentra fuertemente influenciada por las dificultades asociadas a la tenencia de la tierra de estas comunidades y adicionalmente, por haberse reconocido de parte de todos los actores que la mayoría de las afectaciones de la guerra, lo fueron para las comunidades indígenas. Ahora bien, no se puede desconocer es que los territorios ancestrales indígenas fueron el escenario de cruentas confrontaciones y que estas poblaciones quedaron al garete y sin protección del Estado. Nuevamente, ya en un contexto de pos acuerdo, fueron desconocidas por la comunidad colombiana. las iniciativas que beneficien los intereses de las poblaciones indígenas

Es preciso resalta que, si existen alusiones a iniciativas y políticas públicas nacidas del Acuerdo de Paz, lo son porque el día anterior a la firma del primer acuerdo, las comunidades indígenas fueron escuchadas por la mesa de negociaciones, incluyendo aspectos como el desarrollo rural integral con enfoque territorial y la dimensión étnica y los retos de los pueblos y comunidades étnicas en el postconflicto.

Actualmente en países como Colombia, que cuentan con una amplia diversidad étnica; los pueblos indígenas no tienen más alternativas que luchar con las herramientas de autonomía política otorgadas por el Estado, si bien, su condición de acceso a derechos como salud, agua potable y educación es estable, no existe una garantía que asegure el buen vivir de las comunidades y su protección como patrimonio cultural de la humanidad; de la misma manera, respecto al derecho de acceso a la tierra, se encuentra inconcluso hasta que el Estado le dé una verdadera terminación la conflicto armado que los amenaza desde finales del siglo anterior.

Las amenazas globalizadas que enfrentan los pueblos indígenas del mundo no se mitigan con las DUDH y la DUDPI, menos con dictámenes legislativos, que como en el caso colombiano existe diversa normatividad que exige al Estado protección, pero en realidad no se ven manifestada ninguna acción. Continúan la insurgencia de grupos armados en su territorio, asesinan a sus líderes sociales, no se evidencian verdaderas garantías en las necesidades básicas insatisfechas, en la educación, la salud o el agua potable como el caso específico del resguardo San Lorenzo, que en la actualidad viven condiciones precarias que apuntan a exterminar su presencia en el territorio como patrimonio cultural de la humanidad.

En razón a lo anterior, podemos concluir que seguir apoyando la idea, ligada a una propuesta económica neoliberal de globalización de mercado, sobre una "universalidad de derechos" es apoyar, desde la perspectiva de Foucault (1998), el detrimento gradual a nivel social 
e histórico de las grandes minorías. Afortunadamente ya muchas comunidades se han percatado del peligro que alberga esta propuesta económica y vienen desarrollando a nivel comunitario programas para el fortalecimiento de sus procesos identitarios, como son los programas de guardianes de semilla, Escuelas de medicina tradicional, semilleros de guardia indígena, semilleros de gobierno propio y otra gran cantidad de programas que evidencian que las creaciones colectivas pueden llegar a generar procesos resilientes que protegen a sus integrantes y ayudan en la preservación de las culturas mitigando la violencia estructural a las que estos pueblos han sido sometidos históricamente.

\section{Referencias bibliográficas}

Amoroz, I. (2011). El derecho a la salud en comunidades indígenas del Estado de Chiapas. Revista Pueblos y Fronteras Digital, 6 (11), 8-37.

Corte Constitucional de Colombia, (2009). Auto 004. Magistrado ponente: Manuel José Cepeda Espinosa. Recuperado de http://www.corteconstitucional.gov.co/relatoria/ autos/2009/a004-09.htm

Corte Constitucional de Colombia. (2009). Auto 009. Recuperado de http://www. corteconstitucional.gov.co/relatoria/autos/2009/a004-09.htm

Bidaseca, K. (2007). Comunidad y derecho a la tierra: órdenes jurídicos y procesos culturales silenciados. Revista electrónica de Estudios Latinoamericanos, 5 (19), 51-62.

Constitución Política de Colombia de 1991. (2016). Corte Constitucional. Recuperado de https://www.corteconstitucional.gov.co/inicio/Constitucion\%20politica\%20de\%20 Colombia.pdf

Corte Constitucional de Colombia. (2012). Sentencia C-489 de 2012. Magistrada ponente: Adriana María Guillén Arango. Recuperado de http://www.corteconstitucional.gov.co/ RELATORIA/2012/C-489-12.htm

Corte Constitucional de Colombia. (2000). Sentencia SU 1150 de 2000. Magistrado Ponente: Eduardo Cifuentes Muñoz. Recuperado de http://www.corteconstitucional.gov.co/ relatoria/2000/SU1150-00.htm

Declaración de las Naciones Unidas sobre los Derechos de los Pueblos Indígenas. (2007). Naciones Unidas. Recuperado de: https://www.un.org/esa/socdev/unpfii/documents/ DRIPS_es.pdf

Escobar, A. (2008). Territories of Difference: Place, Movements, Life, Redes. Duke University Press.

Falcón, J. (2016). Multiculturalismo y Nueva Constitución. In Quiero F. \& Gajardo J. (Eds.), Por una Asamblea Constituyente Constitución: Mecanismos, procesos y contenidos para una nueva (pp. 195-244). Ciudad Autónoma de Buenos Aires: CLACSO. doi:10.2307/j. ctvtxw27s.12 
Fleck, Ludwik. ([1929]1986). "On the Crisis of “Reality”. En: Cohen, R., Schnelle (ed) Cognition and fact. Materials on Ludwig Fleck. Dordrecht: D. Reidel Pub. Co. Pág: 47-58.

Fleck, Ludwik. ([1935] 1979, 1986). Entstehung und Entwicklung einer wissenschaftlichen Tatsache. Einfiihrung in die Lehre vom Denkstil und Denkkollecktiv. Basel: Benno Schwabe and Co. V.e. Genesis and development of a scientific fact. Chicago: University of Chicago Press. V.e La génesis y el desarrollo de un hecho científico. Madrid: Alianza Editorial.

Foucault, M. (1998). “El sujeto y el poder”. En H. Dreyfus y P. Ravinov. Michel Foucault; más allá del estructuralismo y la hermenéutica. México D.F: UNAM.

Foucault, M. (1999). “Verdad y poder”. Estrategias de poder. Obras esenciales. Vol. II. Barcelona: Paidós.

Galtung, J. (1969). Violence, Peace and Peace Research, Journal of Peace Research 27(3).

Giménez, G. (2005). La Cultura como Identidad y la Identidad como Cultura. Instituto de Investigaciones Sociales. México: UNAM.

La Declaración Universal de los Derechos Humanos. (2015). Naciones Unidas. Recuperado de: https://www.un.org/es/documents/udhr/UDHR_booklet_SP web.pdf

Molina, C. M. (2012). La autonomía educativa indígena en Colombia. Vniversitas, (124), 261292.

Ríos, M., Álvarez; A., Escobar; V., Corrales, C; Escobar, M. (2002). Situación de salud de las comunidades Indígenas nasas, Santander de Quilichao, Cauca. Revista Facultad Nacional de Salud Pública, 20 (2).

Juzgado primero civil del circuito especializado en restitución de tierras de Pereira, Colombia, (19 de diciembre de 2018). Sentencia 025. Recuperado de https://verdadabierta. com/wp-content/uploads/2019/02/Sentencia-Resguardo-San-Lorenzo.pdf

Plan Nacional de Desarrollo 2014-2018 “Todos por un nuevo país”. Ley 1753 de 2015. Recuperado de: https://colaboracion.dnp.gov.co/CDT/Normograma/Ley\%201753\%20 de\%202015.pdf

Tapasco, J. (2016). Lucha y Resistencia del Pueblo Emberá del Alto Occidente de Caldas: Desde la conquista hasta el presente, siglos XVI - XXI. Cabildo Resguardo Indígena San Lorenzo. 